\title{
It's SO Easy Being Green Team Driven Workplace Solutions - Booth \#619
}

\author{
Nicole Shapiro ${ }^{1}$, Angela Tarver ${ }^{1}$, Megan Kennedy ${ }^{2}$, Eric Tang ${ }^{1}$, Natasha Zvenigorodsky ${ }^{1}$, \\ Matthew San Diego ${ }^{1}$, Christine Naca ${ }^{1}$, Melanie Alexandre ${ }^{1}$ \\ ${ }^{1}$ Lawrence Berkeley National Laboratory \\ ${ }^{2}$ Lawrence Livermore National Laboratory
}

March 2011

The work conducted by the U.S. Department of Energy Joint Genome Institute is supported by the Office of Science of the U.S. Department of Energy under Contract No. DE-AC02$05 \mathrm{CH} 112$ 


\section{DISCLAIMER}

This document was prepared as an account of work sponsored by the United States Government. While this document is believed to contain correct information, neither the United States Government nor any agency thereof, nor The Regents of the University of California, nor any of their employees, makes any warranty, express or implied, or assumes any legal responsibility for the accuracy, completeness, or usefulness of any information, apparatus, product, or process disclosed, or represents that its use would not infringe privately owned rights. Reference herein to any specific commercial product, process, or service by its trade name, trademark, manufacturer, or otherwise, does not necessarily constitute or imply its endorsement, recommendation, or favoring by the United States Government or any agency thereof, or The Regents of the University of California. The views and opinions of authors expressed herein do not necessarily state or reflect those of the United States Government or any agency thereof or The Regents of the University of California. 


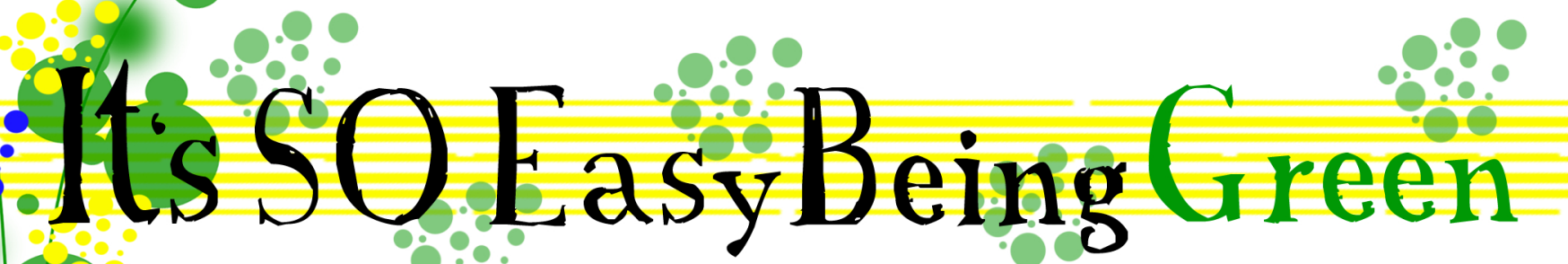
Team Driven Workplace Solutions - Booth \# 619

\section{Problem \\ - Budget constraints require creative solutions to overcome ergonomic challenges}
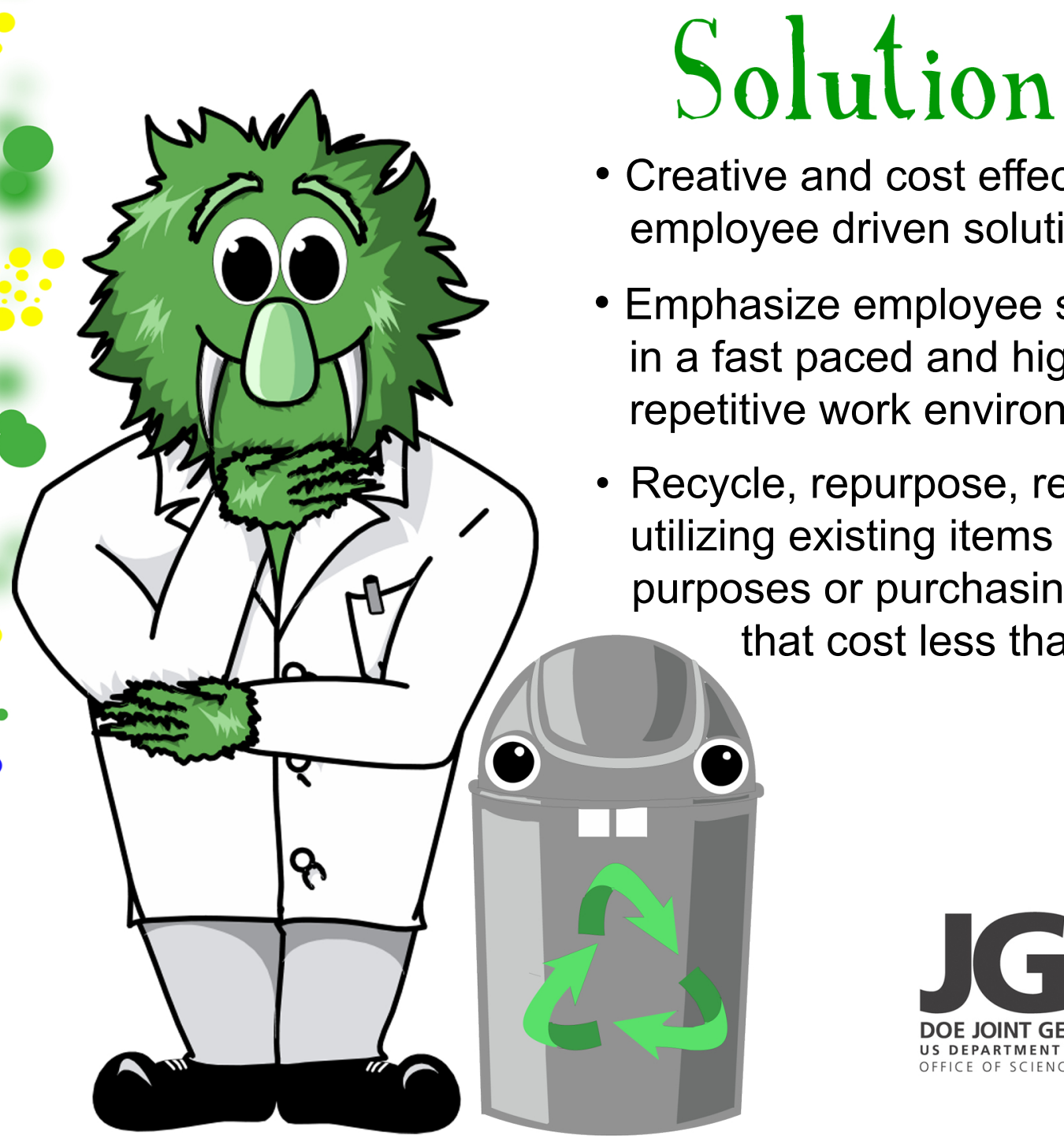

- Creative and cost effective employee driven solutions

- Emphasize employee safety in a fast paced and highly repetitive work environment

- Recycle, repurpose, reuse: utilizing existing items for new purposes or purchasing items that cost less than $\$ 100$

DOE Joint Genome Institute 2800 Mitchell Drive $\cdot$ Walnut Creek, CA 94598 (925) 296-5670 • http://www.jgi.doe.gov/education/ergonomics 


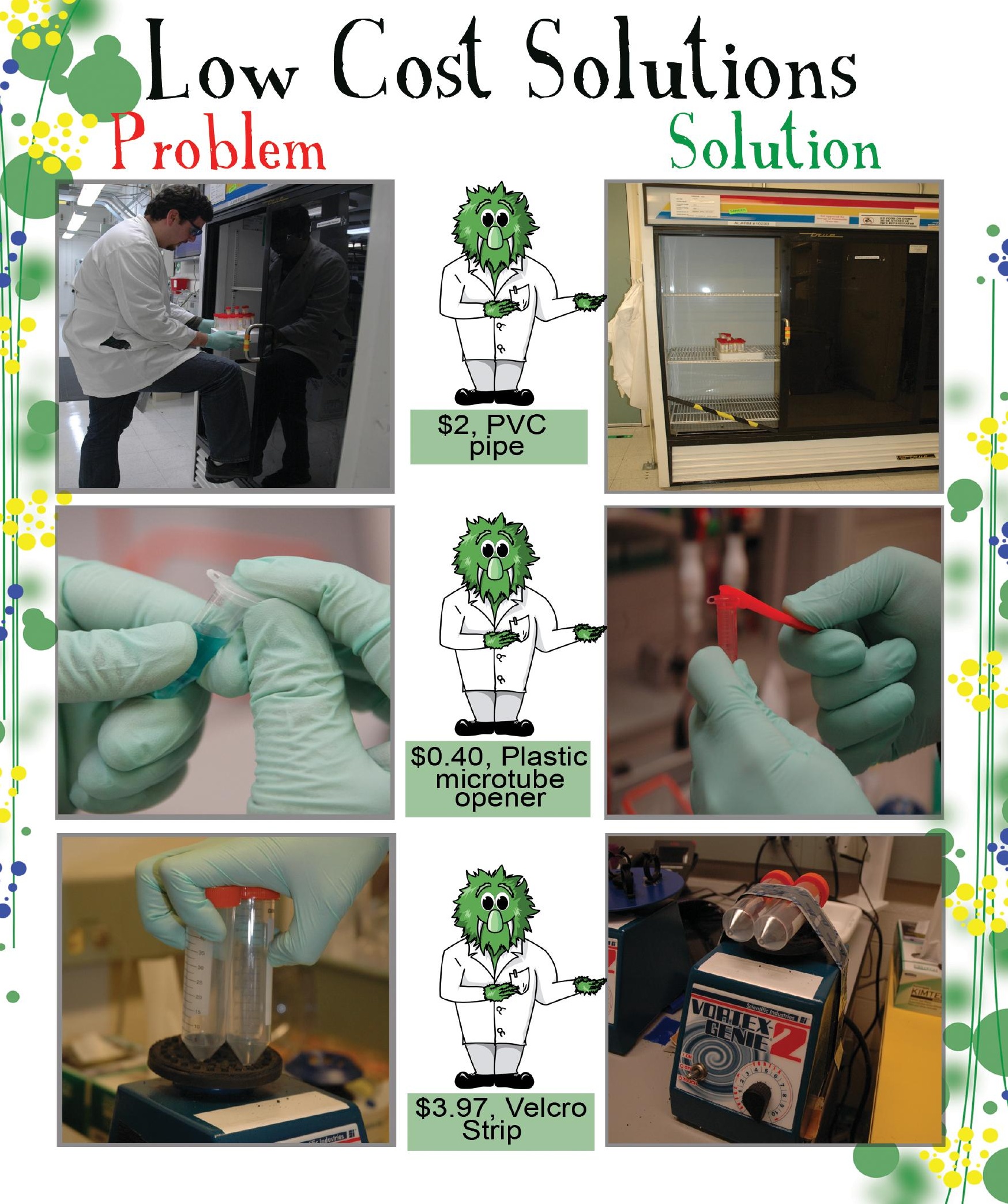


No Cost Solutions

Problem
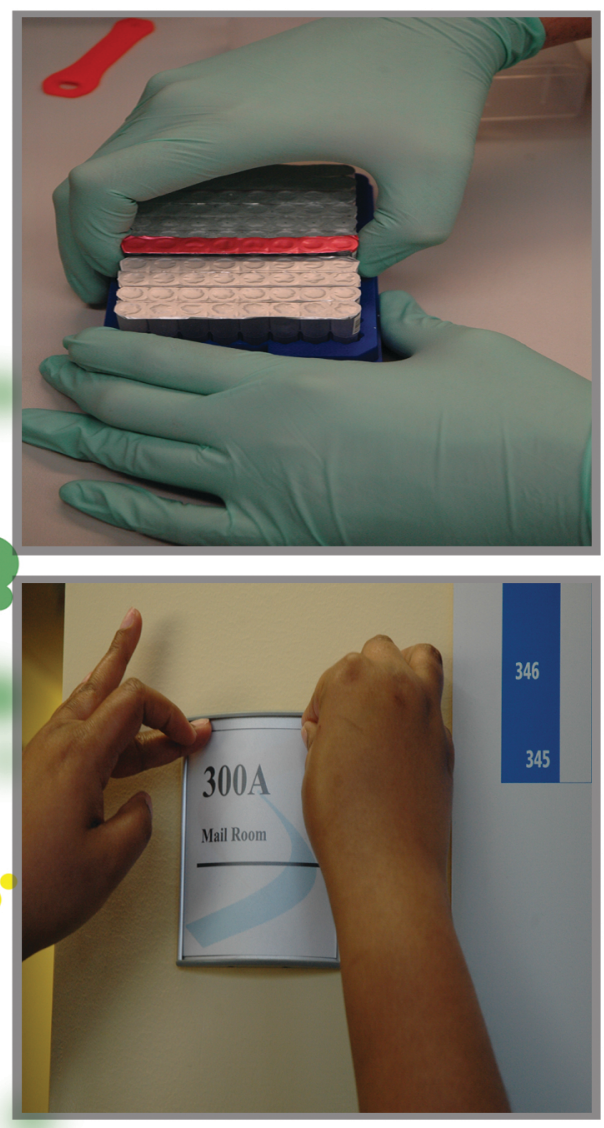

.

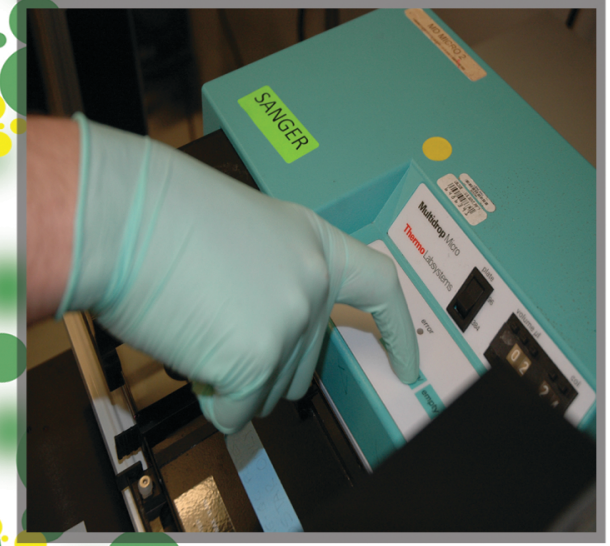

Solution

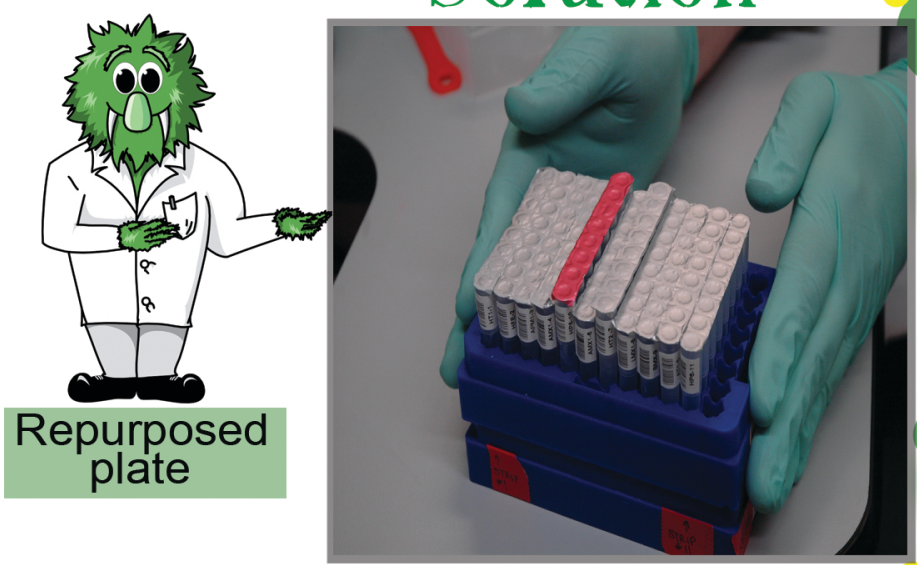

$?$
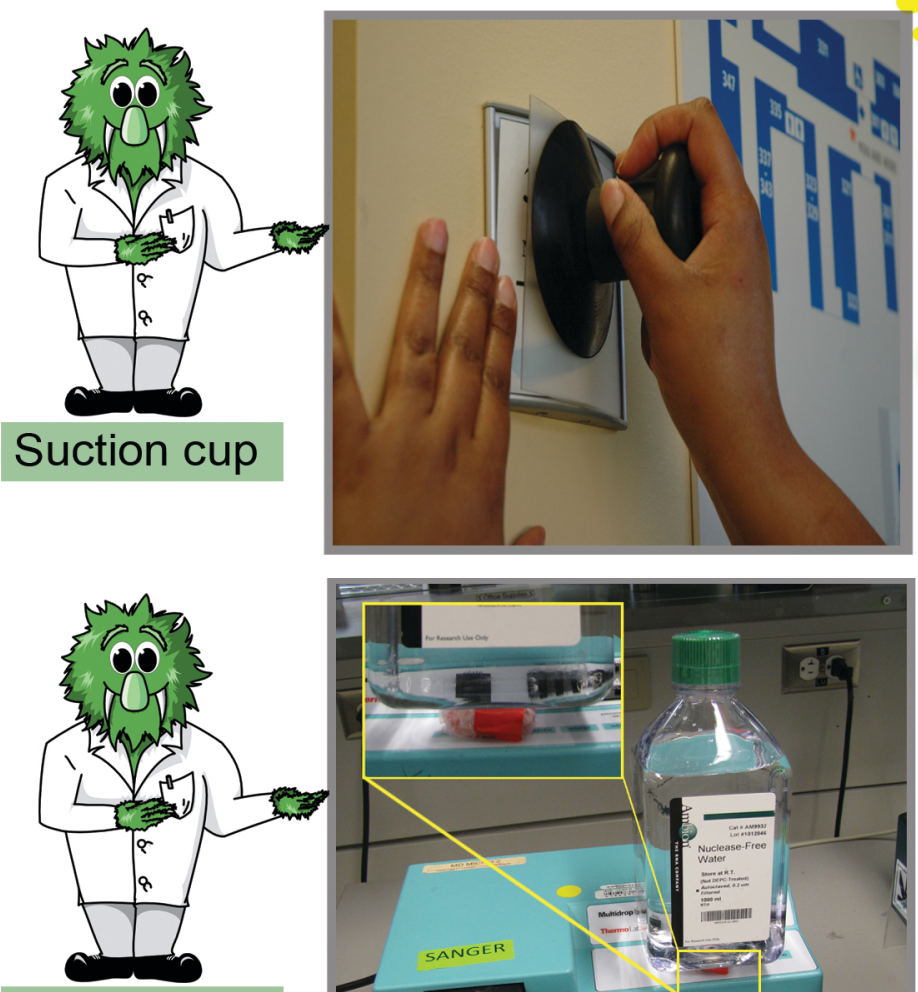

Bubble wrap, tape, water bottle

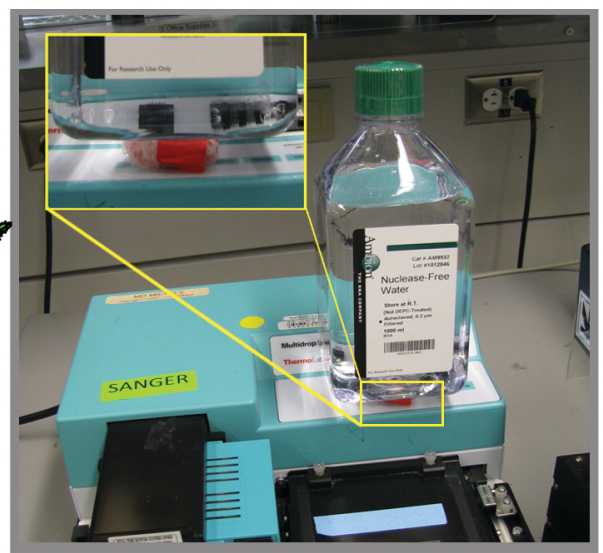




\section{Outcome}

- Safety:

- ZERO Injuries in the production line in 2010

- Cost:

- The expense of eight low cost solutions totaled \$144.15, ( $\$ 18$ per solution): ROI $<3$ hours

- Nineteen reused, recycled or repurposed tools added at no cost: infinite ROI

- Quality:

- Maintained the quality of production samples and increased efficiency

- Delivery:

- Increased production due to increased morale
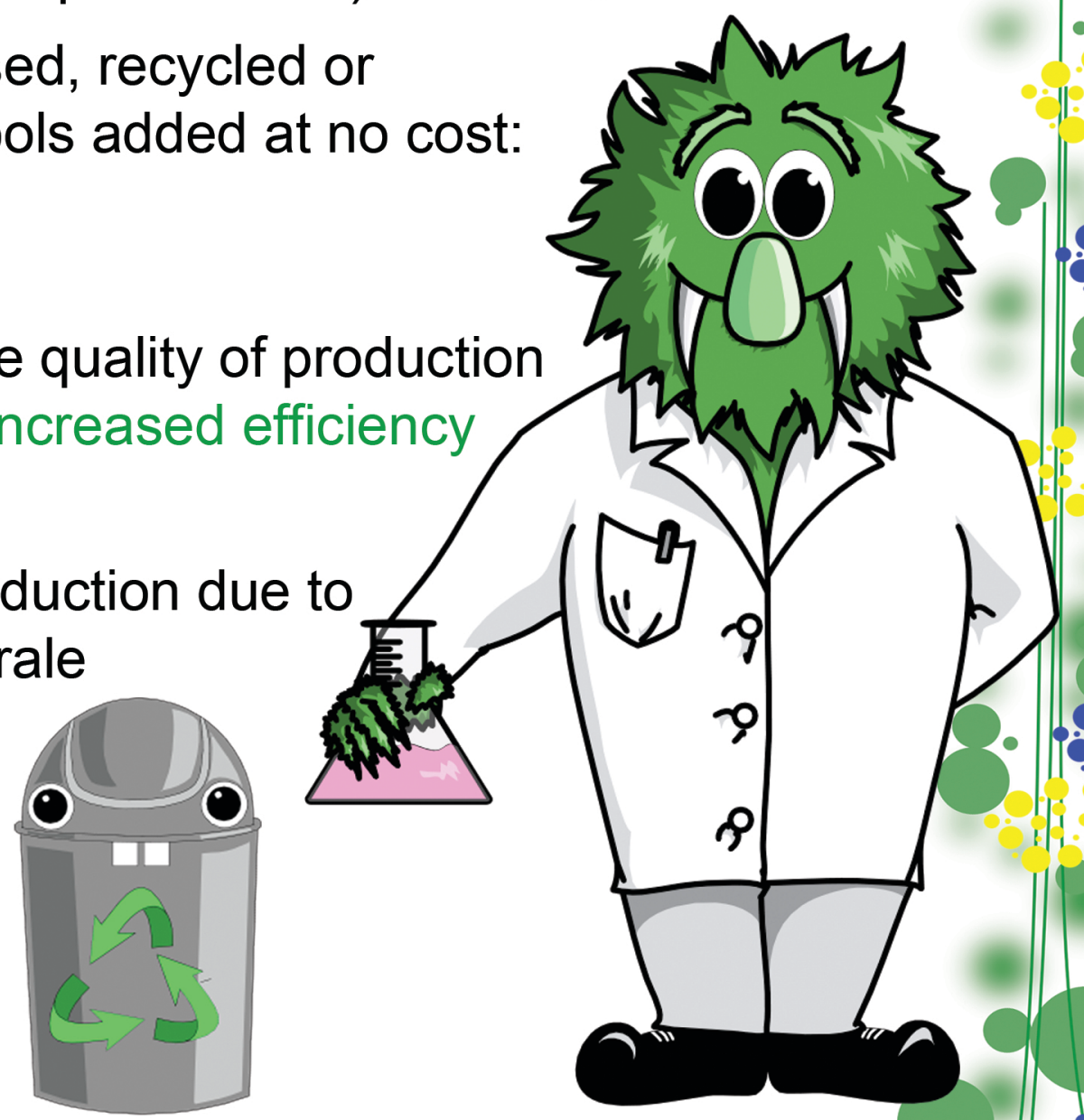

Authors: Nicole Shapiro, Angela Tarver, Megan Kennedy, Eric Tang, Natasha Zvenigorodsky, Matthew San Diego, Christine Naca, Melanie Alexandre

The work conducted by the U.S. Department of Energy Joint Genome Institute is supported by the Office of Science of the U.S. Department of Energy under Contract No. DE-AC02-05CH112 